\title{
Morbidity from repetitive knee trauma in carpet and floor layers
}

\author{
M THUN, ${ }^{1}$ S TANAKA, ${ }^{1}$ A B SMITH, ${ }^{1}$ W E HALPERIN, ${ }^{1}$ S T LEE, ${ }^{1}$ M E LUGGEN, ${ }^{2}$ \\ EVELYN V HESS ${ }^{2}$ \\ From the Division of Surveillance, Hazard Evaluations and Field Studies, ${ }^{1}$ National Institute for Occupational \\ Safety and Health, Centers for Disease Control, Department of Health and Human Services, Cincinnati, Ohio \\ 45226, and Division of Immunology, ${ }^{2}$ Department of Internal Medicine, University of Cincinnati College of \\ Medicine, Cincinnati, Ohio 45267, USA
}

\begin{abstract}
Carpet layers comprise less than $0.06 \%$ of the United States workforce yet they submit $6.2 \%$ of compensation claims for traumatic knee inflammation. Their work involves multiple sources of acute and chronic knee trauma including kneeling, pressure from sharp objects, and use of a device called a "knee kicker" to stretch wall to wall carpet. To characterise the knee morbidity in carpet layers and to identify occupational risk factors, a questionnaire was completed by 112 carpet and floor layers, 42 tile and terrazo setters, and 243 millwrights and bricklayers (MWBL). The MWBL comparison workers seldom kneel and do not use a knee kicker. Physical and $x$ ray examinations were conducted on a subset of 108 respondents to validate the questionnaire responses. Compared with the MWBL, carpet layers reported more frequent bursitis $(20 \% v 6 \%)$, needle aspiration of knee fluid $(32 \% \vee 6 \%)$, and skin infections of the knee $(7 \% v 2 \%)$. A score indicating frequency of using the knee kicker was the only statistically significant predictor of bursitis, whereas the score for kneeling was one of several predictors of knee aspiration and skin infections of the knee. These data suggest that carpet and floor layers experience substantially more knee morbidity than other occupational groups, and that kneeling and use of the knee kicker are risk factors providing opportunities for prevention.
\end{abstract}

Workers who kneel to perform their jobs inflict chronic trauma to their knee joints. Disorders such as the "housemaid's knee" of women who kneel to scrub floors and the "beat knee" of British low seam coalminers, are well recognised. ${ }^{1}$ The former is characteristically a prepatellar bursitis, whereas the latter is often a combination of bursitis and disfiguring localised cellulitis. ${ }^{2-6}$

Carpet and floor layers have received relatively less attention as workers at high risk of knee trauma. Not only do both groups kneel but carpet layers also use a device called the "knee kicker" to stretch the carpet for wall to wall installation. Workers using this tool generate force by striking the suprapatellar area of their knee against the instrument. ${ }^{7}$ In 1982 the National Institute for Occupational Safety and Health (NIOSH) became concerned about knee dis-

Accepted 29 September 1986 ease in carpet layers when one of us (WH) observed the technique of workers installing carpet and learnt of anecdotal reports of knee surgery, evacuation of effusions, and treatment of skin infection among floor layers.

Substantiation of the reports of knee problems among carpet layers was provided by the Bureau of Labor Statistics, supplemental data system. ${ }^{8}$

Carpet layers submit a disproportionately large fraction of the claims for worker's compensation for knee joint inflammation attributed to kneeling, leaning, repetition of pressure, or striking against a stationary object. 9 The estimated 88000 carpet installers in the United States comprise only $0.0575 \%$ of the total workforce (table 1) yet they account for approximately $6.2 \%$ of such claims, a nearly 108 -fold increase.

Because of the concern about chronic knee trauma in carpet and floor layers, we conducted an interview and medical survey to define the nature and mag- 
Table 1 Workers' compensation claims in 1979 for knee joint inflammation attributed to kneeling, leaning, repetition of pressure, or striking against a stationary object*

\begin{tabular}{|c|c|c|c|c|c|}
\hline Occupation & No of claims & $\%$ of claims & $\%$ of workforce & $\begin{array}{l}\text { Occup } \\
\text { knee m } \\
\text { ratiot }\end{array}$ & is \\
\hline $\begin{array}{l}\text { Carpet installers } \\
\text { Tilesetters } \\
\text { Floor layers } \\
\text { Dry wall installers and lathers } \\
\text { Cement and concrete finishers } \\
\text { Brick or stonemasons } \\
\text { Millwrights }\end{array}$ & $\begin{array}{r}46 \\
16 \\
10 \\
10 \\
10 \\
9 \\
3\end{array}$ & $\begin{array}{l}6 \cdot 199 \\
2 \cdot 156 \\
1 \cdot 348 \\
1 \cdot 348 \\
1 \cdot 348 \\
1 \cdot 213 \\
0.404\end{array}$ & $\begin{array}{l}0-0575 \\
0-0410 \\
0-0291 \\
0-0605 \\
0-0814 \\
0.2026 \\
0-1497\end{array}$ & $\begin{array}{r}107 \cdot 81 \\
52 \cdot 59 \\
46 \cdot 32 \\
22 \cdot 28 \\
16 \cdot 56 \\
5 \cdot 99 \\
2 \cdot 70\end{array}$ & बे \\
\hline
\end{tabular}

nitude of the knee morbidity and to identify causative factors that might be eliminated or controlled.

\section{Participants and methods}

\section{HY POTHESES}

The question of interest was whether carpet layers, who both kneel and strike their knees repeatedly against the knee kicker have an increased prevalence of reported knee symptoms and of physical and radiological abnormalities compared with workers who neither kneel nor use this tool. A secondary question was whether the increased knee morbidity, if it occurs, results from repetitive use of the knee kicker, chronic kneeling, or both.

\section{STUDY POPULATION}

The study was initially requested by the Resilient Floor Layers and Decorators' Union, Local 873. This union Local represents an estimated $20-33 \%$ of car- pet and floor layers in Cincinnati, Ohio. Two other union Locals in Cincinnati also agreed to participate as comparison populations (fig 1). Because each of the three unions included workers from multiple trades, subjects were recategorised in the analysis into three activity categories reflecting the exposures of interest (fig 1). Reassignment was based on the worker's description of his usual occupation. Carpat layers were grouped with other resilient floor layers since both groups kneel and use a knee kicker whep installing carpet. Tilesetters, terrazzo, mosaic and stone layers were grouped together as workers whe kneel extensively but do not use a knee kicker. Wilitwrights, bricklayers, and decorators (MWBL) grouped together as workers who kneel only intermis tently and never use a knee kicker. Bricklayers stand when erecting walls and millwrights kneel only inte\% mittently when assembling industrial fixtures and machinery. To our knowledge, no trade group uses $\vec{\beta}$ knee kicker in the absence of kneeling.

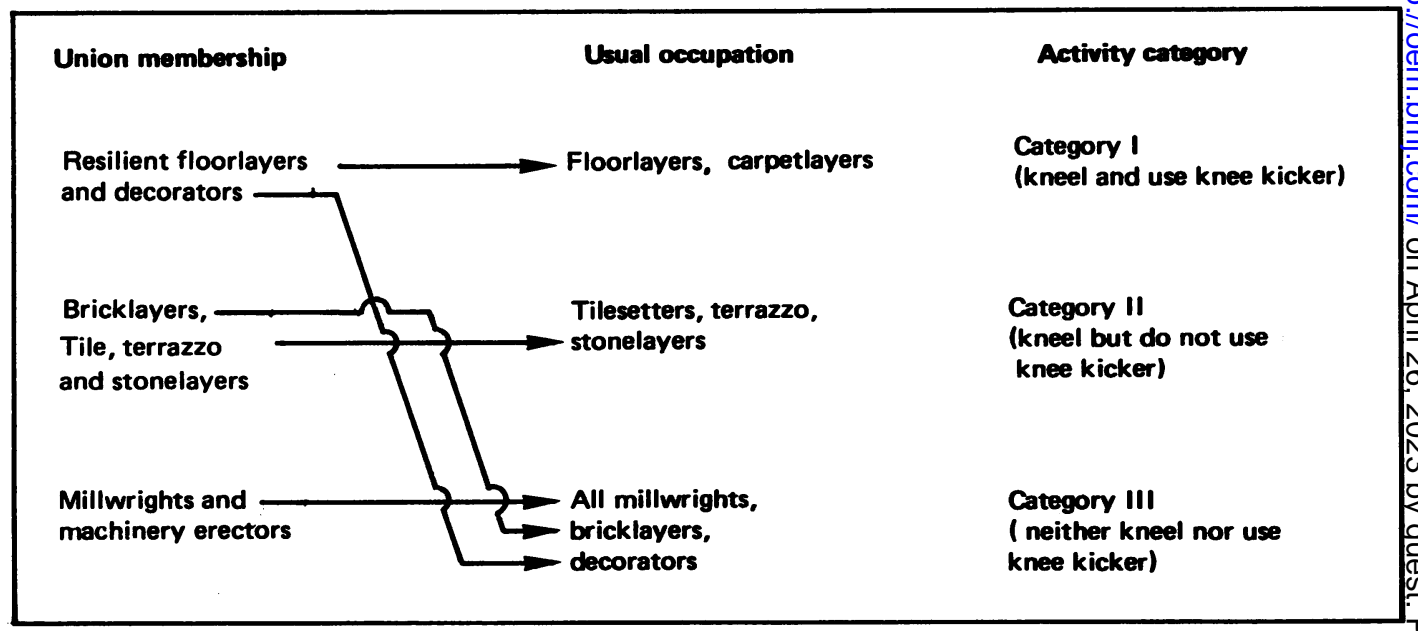

Fig 1 Categorisation of workers according to union membership: occupation and activity category. 
SAMPLING STRATEGY

All active fioor layers, and one third of currently active members of the larger Bricklayers' and Millwrights and Machinery Erectors' unions were invited to participate. All retired workers were also sampled, regardless of union membership. Although the purpose of including retired workers was to minimise losses from the study due to premature retirement from knoe disease, only retired workers who paid their dues were listed on the union register. Thus workers who had ceased paying dues after leaving the trade were lost.

\section{OUTCOMES MEASURED}

The study consisted of two questionnaires and a medical examination (fig 2). Initially a self administered questionnaire, developed by us, was posted to all workers selected to participate. Questions inquired about the lifetime prevalence of seven knee conditions (appendix A). The questionnaire also inquired about non-occupational knee injury, personal characteristics (age, weight, and height), and work practices (retirement status, usual occupation, use of the knee kicker, use of the power carpet stretcher, and percentage of time spent kneeling, standing, or squatting while at work).

A second interview was subsequently administered by telephone to all respondents to the initial questionnaire. Trained interviewers asked standardised questions about seven symptoms of knee disease from the arthritis supplement of the National Health and Nutrition Examination Survey (NHANES). ${ }^{10}$ Symptoms included knee pain, swelling and tenderness to touch. The purpose of these questions (appendix B) was to provide standardised information about symptom prevalence that could be compared with the United States male population.

\section{MEDICAL EXAMinations}

Physical and $x$ ray examinations of the knee were offered to everyone who completed the self administered and telephone questionnaires who resided in Indiana, Kentucky or Ohio. The medical examination data were not intended to be representative of the entire study group; rather, they were obtained to validate the questionnaire responses. Knee examinations were conducted by eight physician faculty and fellow members of the University of Cincinnati division of immunology/rheumatology. Participants were randomly assigned to one of these eight physicians who were unaware of the subject's occupation or medical history. The examiners assessed gait, lower leg alignment, tibial torsion, knee skin changes, patellar bursitis, knee joint mobility, crepitation, tenderness,

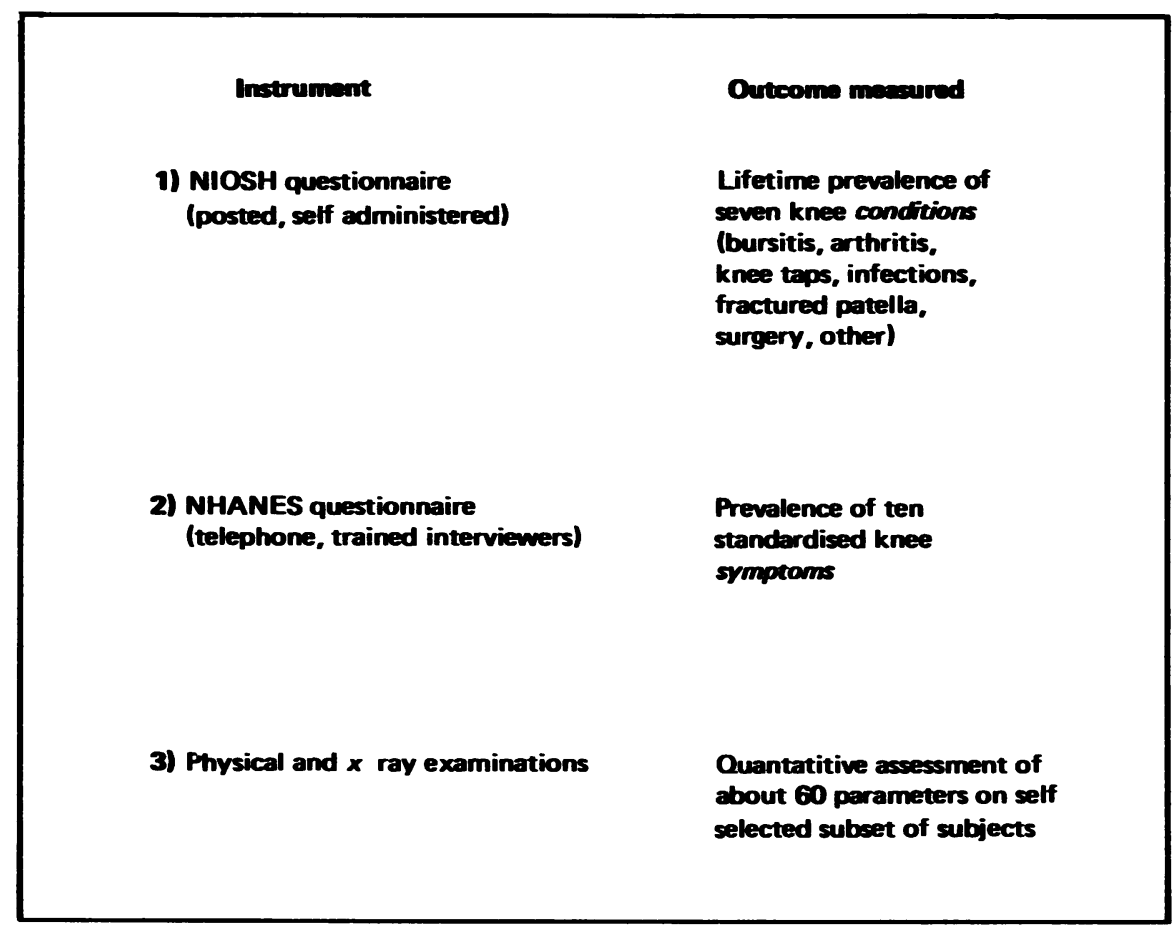

Fig 2 Outcomes measured in knee study. 
614

swelling, pain, ligament stability, meniscus, and measurements for girth and range of motion of knee joint.

Knee $x$ ray films included anteroposterior, lateral, tunnel, and axial views. Two radiologists separately reviewed the films for a variety of outcomes: (1) osseous spurs, erosions, cysts, or sclerosis of either the distal femur or the proximal tibia; (2) narrowing of the knee joint space; (3) patellar spurs; (4) approximation of the patella to the femur; (5) loose bodies; (6) osteochondromatosis; (7) chondrocalcinosis; (8) soft tissue calcification; and (9) suprapatellar effusion. Because of the low rate of participation in the physical and $x$ ray examinations, only those data used to validate the questionnaire responses will be reported here.

\section{DATA TRANSFORMATION}

Two different classification schemes were used to reflect exposure status in the analysis. The crudest measure was the trichotomy of "activity categories" seen in fig 1. As discussed, these activity categories provided a qualitative measure of whether the usual job necessitated both kneeling and use of the knee kicker, kneeling alone, or neither. A more quantitative, although still subjective, measure of exposure was the score with which each worker described the frequency of standing, sitting, squatting, bending, kneeling, heavy lifting, and use of knee pads, a knee
Thun, Tanaka, Smith, Halperin, Lee, Luggen, Hess kicker, or of a power carpet stretcher. Workers rated each activity on a scale of from one (never) to si (always). To simplify these scores, we subsequently? reduced the categories to three: 1-2 (seldom), 3(intermediate), and 5-6 (frequent). We then used fac? tor analysis to combine pairs of related working pose tures into groups. The resultant three pairs of working postures were bending/lifting (factor 1)? kneeling/standing (factor 2), and sitting/squatting (factor 3). Kneeling and standing were inversely related to each other, whereas the other two posture pairs were related directly.

DATA ANALYSIS

To compare the prevalence of various knee problem $₫$ among the three "occupational activity groups," we first excluded from the analysis the single woman and the 34 subjects with a history of sports injuries to the knee. We then computed the age adjusted prevalence of each of the seven knee conditions in each of the three occupational activity groups. The age distribu= tion of the entire study group provided the standard population. The prevalence in millwrights and bricks layers (MWBL) was used as the denominator in come puting the prevalence ratio for "reported kneg conditions" (table 2) and the prevalence in the NHANES sample of United States men was used ass the referent value in computing prevalence ratios fop $_{0}$

Table 2 Age adjusted prevalence and prevalence ratio of reported knee conditions in floor layers and tilesetters relative to millwrights and bricklayers (MWBL)

\begin{tabular}{|c|c|c|c|c|}
\hline Knee condition & Occupation & Prevalence (\%)* & Prevalence ratio $\dagger$ & 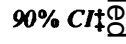 \\
\hline Knee "taps" & $\begin{array}{l}\text { Floor layers } \\
\text { Tilesetters } \\
\text { MWBL }\end{array}$ & $\begin{array}{r}31 \cdot 5 \\
31 \cdot 0 \\
6 \cdot 3\end{array}$ & $\begin{array}{l}5.0 \\
4.9 \\
1 \cdot 0\end{array}$ & $\begin{array}{l}3.2-7.8 \text { 家 } \\
2 \cdot 7-8.7 \\
\text { NA }\end{array}$ \\
\hline Bursitis & $\begin{array}{l}\text { Floor layers } \\
\text { Tilesetters } \\
\text { MWBL }\end{array}$ & $\begin{array}{r}20 \cdot 0 \\
11 \cdot 2 \\
6 \cdot 2\end{array}$ & $\begin{array}{l}3.2 \\
1.8 \\
1.0\end{array}$ & 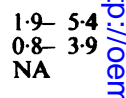 \\
\hline Arthritis & $\begin{array}{l}\text { Floor layers } \\
\text { Tilesetters } \\
\text { MWBL }\end{array}$ & $\begin{array}{l}14 \cdot 3 \\
25 \cdot 7 \\
12 \cdot 9\end{array}$ & $\begin{array}{l}1 \cdot 1 \\
2 \cdot 0 \\
1 \cdot 0\end{array}$ & $\begin{array}{l}0.7-1.8 \\
1.2-3.3 \frac{0}{3} \\
\text { NA }\end{array}$ \\
\hline Skin infections of knee & $\begin{array}{l}\text { Floor layers } \\
\text { Tilesetters } \\
\text { MWBL }\end{array}$ & $\begin{array}{l}7.0 \\
2.6 \\
1.7\end{array}$ & $\begin{array}{l}4 \cdot 1 \\
1.5 \\
1.0\end{array}$ & $\begin{array}{l}1.5-10.8 \\
0.3-8.2 \\
\text { NA 을 }\end{array}$ \\
\hline Fractured patella & $\begin{array}{l}\text { Floor layers } \\
\text { Tilesetters } \\
\text { MWBL }\end{array}$ & $\begin{array}{l}0 \\
0 \\
3 \cdot 7\end{array}$ & $\begin{array}{l}0.0 \\
0.0 \\
1.0\end{array}$ & - \\
\hline Knee surgery & $\begin{array}{l}\text { Floor layers } \\
\text { Tilesetters } \\
\text { MWBL }\end{array}$ & $\begin{array}{l}2 \cdot 4 \\
7 \cdot 6 \\
6 \cdot 1\end{array}$ & $\begin{array}{l}0 \cdot 4 \\
1 \cdot 3 \\
1 \cdot 0\end{array}$ & 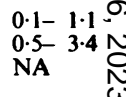 \\
\hline Other knee conditions & $\begin{array}{l}\text { Floor layers } \\
\text { Tilesetters } \\
\text { MWBL }\end{array}$ & $\begin{array}{r}19 \cdot 1 \\
16 \cdot 2 \\
9 \cdot 5\end{array}$ & $\begin{array}{l}2.0 \\
1.7 \\
1.0\end{array}$ & $\begin{array}{l}1.3-3.1 \\
0.9-3.30 \\
\text { NA }\end{array}$ \\
\hline \multicolumn{5}{|c|}{$\begin{array}{l}\text { *Age adjusted prevalence directly standardised using the age distribution of the entire study group as the standard population. } \\
\dagger \text { Ratio of age adjusted prevalence in the exposed relative to millwrights and bricklayers. } \\
\$ 90 \% \text { confidence intervals for the directly standardised prevalence ratio using method from Kleinbaum and Kupper. }{ }^{11}\end{array}$} \\
\hline
\end{tabular}


the NHANES questions (table 3). The age distribution of the NHANES weighted sample of men was used as the standard population for direct standardisation. Ninety per cent confidence intervals were computed around the directly standardised prevalence ratios using the standardised risk ratio. ${ }^{11}$

\section{MULTIVARIATE ANALYSES}

Unconditional logistic regression (SAS Logist) was used to identify those personal and occupational characteristics that best predicted any of the seven reported knee conditions. Variables considered in the model included age, usual occupation, duration of employment, the self reported score for use of the knee kicker, postural factors 1-3, and all two way interactions. Main effect variables and interaction terms were retained if the $p$ value was less than 0.05 .
Odds ratios and $90 \%$ confidence intervals were calculated from the model using the lowest use category as the referent. ${ }^{11}$ We report only the final and most parsimonious models for bursitis, knee taps, and skin infections, the three conditions for which the floor layers reported a significant excess.

\section{USE OF THE PHYSICAL AND XRAY \\ EXAMINATIONS TO VALIDATE THE \\ QUESTIONNAIRE DATA}

Physical examination and radiological findings were used to validate the questionnaire responses. Although we expected only certain findings such as arthritis, history of knee surgery, or fractured patella to be documentable on the medical examination, we also included bursitis in the validation study.

Table 3 Prevalence of seven NHANES knee symptoms* in the three occupational groups interviewed and prevalence ratios relative to United States white men, aged 25-74

\begin{tabular}{|c|c|c|c|c|}
\hline Symptom* & Occupation & Prevalence (\%)† & Prevalence ratio & $90 \% \mathrm{CI}_{\ddagger}$ \\
\hline Knee pain for at least one month & $\begin{array}{l}\text { Floor layers } \\
\text { Tilesetters } \\
\text { MWBL }\end{array}$ & $\begin{array}{l}33 \cdot 4 \\
34 \cdot 1 \\
23 \cdot 1\end{array}$ & $\begin{array}{l}3 \cdot 5 \\
3 \cdot 6 \\
2 \cdot 4\end{array}$ & $\begin{array}{l}2.8-4.5 \\
2.1-6.1 \\
1.9-3.0\end{array}$ \\
\hline Swelling and painful to touch & $\begin{array}{l}\text { Floor layers } \\
\text { Tilesetters } \\
\text { MWBL }\end{array}$ & $\begin{array}{r}15 \cdot 4 \\
5 \cdot 6 \\
7 \cdot 2\end{array}$ & $\begin{array}{l}8 \cdot 4 \\
3 \cdot 1 \\
4 \cdot 0\end{array}$ & $\begin{array}{l}5 \cdot 6-12 \cdot 7 \\
1 \cdot 3-7 \cdot 0 \\
2 \cdot 6-6 \cdot 2\end{array}$ \\
\hline Locking of the knee & $\begin{array}{l}\text { Floor layers } \\
\text { Tilesetters } \\
\text { MWBL }\end{array}$ & $\begin{array}{l}6 \cdot 8 \\
5 \cdot 3 \\
5 \cdot 4\end{array}$ & $\begin{array}{l}7.0 \\
5.5 \\
5.6\end{array}$ & $\begin{array}{l}3 \cdot 6-13 \cdot 9 \\
2 \cdot 1-14 \cdot 3 \\
3 \cdot 1-11 \cdot 2\end{array}$ \\
\hline Knee "gives away" & $\begin{array}{l}\text { Floor layers } \\
\text { Tilesetters } \\
\text { MWBL }\end{array}$ & $\begin{array}{r}17 \cdot 0 \\
9 \cdot 7 \\
11 \cdot 2\end{array}$ & $\begin{array}{l}4 \cdot 9 \\
2 \cdot 8 \\
3 \cdot 2\end{array}$ & $\begin{array}{l}3 \cdot 4-7 \cdot 3 \\
1 \cdot 3-6 \cdot 1 \\
2 \cdot 1-4 \cdot 6\end{array}$ \\
\hline Pain at rest & $\begin{array}{l}\text { Floor layers } \\
\text { Tilesetters } \\
\text { MWBL }\end{array}$ & $\begin{array}{l}22 \cdot 1 \\
28 \cdot 8 \\
13 \cdot 9\end{array}$ & $\begin{array}{l}5 \cdot 0 \\
6 \cdot 5 \\
3 \cdot 1\end{array}$ & $\begin{array}{l}3 \cdot 6-6 \cdot 9 \\
3 \cdot 5-12 \cdot 2 \\
2 \cdot 3-4 \cdot 3\end{array}$ \\
\hline Swelling of knee joint & $\begin{array}{l}\text { Floor layers } \\
\text { Tilesetters } \\
\text { MWBL }\end{array}$ & $\begin{array}{l}19 \cdot 2 \\
19 \cdot 7 \\
12 \cdot 7\end{array}$ & $\begin{array}{l}4 \cdot 9 \\
5 \cdot 0 \\
3 \cdot 2\end{array}$ & $\begin{array}{l}3.4-7.0 \\
2.2-11.7 \\
2.3-4.6\end{array}$ \\
\hline Morning stiffness & $\begin{array}{l}\text { Floor layers } \\
\text { Tilesetters } \\
\text { MWBL }\end{array}$ & $\begin{array}{l}22 \cdot 7 \\
14 \cdot 5 \\
22 \cdot 2\end{array}$ & $\begin{array}{l}3 \cdot 8 \\
2 \cdot 4 \\
3 \cdot 7\end{array}$ & $\begin{array}{l}2.8-5.3 \\
1.4-4.3 \\
3.0-4.7\end{array}$ \\
\hline
\end{tabular}

* Symptoms were those used in the NHANES standardised supplemental questionnaire on arthritis.

†Prevalence has been age adjusted using direct standardisation, with men in the NHANES sample as the standard population.

$\$ 90 \%$ confidence intervals for the directly standardised prevalence ratio using the method described for the standardised risk ratio. ${ }^{11}$

Table 4 Participation in knee disease study by union membership

\begin{tabular}{|c|c|c|c|c|}
\hline \multirow[b]{2}{*}{ Union } & \multirow[b]{2}{*}{ No of members } & \multirow[b]{2}{*}{ No sampled for study } & \multicolumn{2}{|l|}{ Participation } \\
\hline & & & $\begin{array}{l}\text { Questionnaires } \\
\text { No (\%) }\end{array}$ & $\begin{array}{l}\text { Medical } \\
\text { No }(\%)\end{array}$ \\
\hline $\begin{array}{l}\text { Resilient floor layers and decorators } \\
\text { Bricklayers, terrazo, mosaic, and tilelayers } \\
\text { Millwrights and machinery erectors }\end{array}$ & $\begin{array}{l}170 \\
440 \\
420\end{array}$ & $\begin{array}{l}170 \\
190 \\
202\end{array}$ & $\begin{array}{l}132(78 \%) \\
146(77 \%) \\
154(76 \%)\end{array}$ & $\begin{array}{l}47(28 \%) \\
40(21 \%) \\
21(10 \%)\end{array}$ \\
\hline Totals & 1030 & 562 & $432(77 \%)$ & $108(19 \%)$ \\
\hline
\end{tabular}


VALIDATION USING PHYSICIAN'S RECORDS

We attempted to contact the physicians of workers reporting specific knee conditions in order to validate their diagnoses.

\section{Results}

Table 4 shows the number of workers participating in the questionnaire and medical phases of the study, categorised by union membership. Participation could be assessed only by union membership rather than "usual occupation," since the latter was determined only on participants in the questionnaire study. Almost identical proportions of workers sam-

Table 5 Demographic characteristics of workers participating in the questionnaire survey, grouped by usual occupation

\begin{tabular}{|c|c|c|c|}
\hline & $\begin{array}{l}\text { Carpet and } \\
\text { floor layers } \\
\text { (floor layers) } \\
(n=112)\end{array}$ & $\begin{array}{l}\text { Tile terrazo } \\
\text { marblesetters } \\
\text { (tilesetters) } \\
(n=42)\end{array}$ & $\begin{array}{l}\text { Millwrights, } \\
\text { bricklayers, } \\
\text { decorators } \\
(M W B L) \\
(n=243)\end{array}$ \\
\hline \multicolumn{4}{|l|}{ Age: } \\
\hline Mean & $50 \cdot 7$ & 57.8 & 53.9 \\
\hline $\begin{array}{l}\text { SD } \\
\text { Range }\end{array}$ & $15 \cdot 1$ & 15.8 & $16 \cdot 0$ \\
\hline Range & 23-79 & $24-86$ & $19-87$ \\
\hline \multicolumn{4}{|c|}{ Years employed: } \\
\hline Mean & $25 \cdot 0$ & $31 \cdot 2$ & $24 \cdot 3$ \\
\hline SD & $12 \cdot 1$ & $14 \cdot 1$ & $12 \cdot 8$ \\
\hline Range & $1.5-47.6$ & $5 \cdot 3-61$ & $1 \cdot 2-61$ \\
\hline \multicolumn{4}{|c|}{ Height (inches): } \\
\hline Mean & $70 \cdot 0$ & $70 \cdot 0$ & $70 \cdot 0$ \\
\hline SD & $2 \cdot 7$ & $3 \cdot 3$ & $2 \cdot 6$ \\
\hline \multicolumn{4}{|c|}{ Weight (kg): } \\
\hline Mean & $80 \cdot 1$ & $80 \cdot 7$ & $81 \cdot 3$ \\
\hline SD & $12 \cdot 7$ & $11 \cdot 1$ & $13 \cdot 4$ \\
\hline Range & $47 \cdot 6-113 \cdot 4$ & $59 \cdot 0-115 \cdot 7$ & $45 \cdot 4-117 \cdot 9$ \\
\hline
\end{tabular}

Table 6 Selected job characteristics of participants in the questionnaire survey, by usual occupation

\begin{tabular}{|c|c|c|c|}
\hline & $\begin{array}{l}\text { Carpet and } \\
\text { floor layers } \\
(\text { floor layers }) \\
(n=112)\end{array}$ & $\begin{array}{l}\text { Tile terrazo } \\
\text { marblesetters } \\
\text { (tilesetters) } \\
(n=42)\end{array}$ & $\begin{array}{l}\text { Millwrights, } \\
\text { bricklayers, } \\
\text { decorators } \\
(M W B L) \\
(n=243)\end{array}$ \\
\hline \multicolumn{4}{|l|}{ Knee kicker score* } \\
\hline Mean & 3.9 & $1 \cdot 0$ & $1 \cdot 1$ \\
\hline SD & $1 \cdot 8$ & 0.0 & 0.6 \\
\hline Range & $1-6$ & $1-1$ & $1-6$ \\
\hline \multicolumn{4}{|l|}{ Kneeling score* } \\
\hline Mean & $5 \cdot 5$ & $4 \cdot 9$ & $2 \cdot 9$ \\
\hline SD & 6 & 5 & 3 \\
\hline Range & $1-6$ & $1-6$ & $1-6$ \\
\hline \multicolumn{4}{|l|}{ Any kneeling } \\
\hline No (\%) & $111(99 \%)$ & $41(97 \%)$ & $210(83 \%)$ \\
\hline \multirow{2}{*}{$\begin{array}{l}\text { Regularly use knee } \\
\text { pads } \dagger \\
\% \text { of time using knee } \\
\text { pads } \dagger \text { (mean) }\end{array}$} & $57(51 \%)$ & $34(97 \%)$ & $31(15 \%)$ \\
\hline & $43 \cdot 4 \%$ & $83.4 \%$ & $29 \cdot 9 \%$ \\
\hline
\end{tabular}

*Self assigned qualitative score from 1 (never) to 6 (always). $\uparrow$ Analyses restricted to workers who kneel at work.
Thun, Tanaka, Smith, Halperin, Lee, Luggen, Hes pled from the three unions participated in the ques? tionnaire phase of the study (76-78\%); only $19 \%$ of workers sampled participated in the medical exam ination.

Table 5 shows some demographic characteristics $\bar{\Phi}$ the participants in the questionnaire survey. In the and subsequent tables the study subjects are classifieg by "usual occupation" instead of by union memb bership. Slight differences in age and employment stą tus are evident between the three groups. Floor layers. were on average younger and less likely to be retired than either of the two other groups. The tile terrazo and marblesetters $(n=42)$ were slightly older an had been employed the longest; they included tho largest proportion of retired workers.

Table 6 summarises some of the job practices of thi three occupational groups. As may be seen, only floog layers used a knee kicker frequently. Over $80 \%$ of workers in all three groups stated that their work entailed some kneeling, but floor layers and tilesetters reported substantially higher kneeling scores than the MWBL. Among workers who knelt regularly in theen job, tilesetters were far more likely to use knee pad (97\% v $51 \%)$.

Table 2 shows the prevalence of reported knee cont ditions among floor layers and tilesetters compared. with the MWBL. Floor layers more frequegil 18 reported a history of knee tap (needle aspiration of

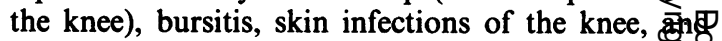
"other knee disease" than the MWBL. Other knee conditions included miscellaneous conditions such $2 \frac{5}{5}$ ruptured cartilage, strained ligament, or puncturs

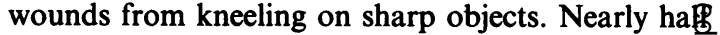
$(47 \%)$ of the floor layers reported having had at least one episode of either knee aspiration or bursitis, coms pared with only $11 \%$ of the MWBL. For knee tapss arthritis, and knee surgery, the small group of tito terrazo and marble setters reported prevalences that were equal to or greater than those of the resilien floor layers. Arthritis was the single condition that tilesetters reported statistically more frequently tha did the MWBL, but floor layers did not.

A similar pattern was evident when comparing the age adjusted prevalence of the seven NHANES symptoms among these workers with that of the NHANES sample. Table 3 shows the age adjusted prevalence of these symptoms in each occupational group. Here. each occupational group is compared with men of comparable age in the NHANES sample of the United States population rather than with the MWBL. Relative to United States men, floor layers reported three to four times the age adjusted preva< lence of all seven symptoms, with the highest prevas lence ratios for swelling and tenderness to touch an locking of the knee joint. Symptom reporting was highest among carpet layers but also significantl ${ }^{D}$ 
higher among tilesetters and even among the millwrights and bricklayers than that of United States men. The millwrights and bricklayers reported a two to sixfold higher prevalence of all symptoms than men in the NHANES sample.

\section{USE OF THE PHYSICAL AND XRAY \\ EXAMINATIONS TO VALIDATE THE \\ QUESTIONNAIRE DATA}

Low participation in the physical and $x$ ray examinations precluded comparison of medical findings between the occupational groups. The physical and $x$ ray data did allow validation of some questionnaire responses, however. Table 7 shows the correspondence between a questionnaire report of bursitis or arthritis and the physical or $x$ ray findings. In these analyses the questionnaire report is considered the screening test; the physical or radiological signs of disease are accepted as the confirmatory "gold standard." For both bursitis and arthritis, the questionnaire response shows low (38-44\%) sensitivity but moderate $(82-89 \%)$ specificity.

For arthritis, the radiologists classified many more subjects as having joint changes consistent with "arthritis" than did the questionnaire or the physical examination. The radiologist identified 32 subjects with some degree of osteoarthritis compared with the physical examination finding of 12 and the questionnaire report of 22. Although more subjects may have reported symptoms of arthritis on questionnaire, only 22 responded positively to question 3, appendix A. A

Table 7 Correspondence between the questionnaire report and summary impression of bursitis and arthritis on physical or x ray examination

\begin{tabular}{|c|c|c|c|c|}
\hline \multirow{2}{*}{\multicolumn{5}{|c|}{$\begin{array}{l}\text { Bursitis } \\
\text { Physical examination: summary impression }\end{array}$}} \\
\hline & & & & \\
\hline $\begin{array}{l}\text { Questionnaire response: } \\
\text { Bursitis + }\end{array}$ & $\stackrel{+}{8}$ & $\overline{14}$ & 22 & \multirow{3}{*}{$\begin{array}{l}\text { Sensitivity } \\
=38 \% \\
\text { Specificity } \\
=84 \%\end{array}$} \\
\hline Bursitis - & 13 & 73 & 86 & \\
\hline Total & 21 & 87 & 108 & \\
\hline \multicolumn{5}{|c|}{$\begin{array}{l}\text { Arthritis } \\
\text { Physical examination: summary impression }\end{array}$} \\
\hline Questionnaire response: & $\begin{array}{l}\text { Arthritis } \\
+\end{array}$ & Arthritis & Total & \multirow{4}{*}{$\begin{array}{c}\text { Sensitivity } \\
=42 \% \\
\text { Specificity } \\
=82 \%\end{array}$} \\
\hline Arthritis + & 5 & 17 & 22 & \\
\hline Arthritis - & 7 & 79 & 86 & \\
\hline Total & 12 & 96 & 108 & \\
\hline \multicolumn{5}{|c|}{$X$ ray examination: summary impression } \\
\hline $\begin{array}{l}\text { Questionnaire response: } \\
\text { Arthritis + }\end{array}$ & $\stackrel{+}{14}$ & & 22 & \multirow{3}{*}{$\begin{array}{r}1 \\
\text { Sensitivity } \\
=43 \cdot 8 \% \\
\text { Specificity } \\
=89 \cdot 3 \%\end{array}$} \\
\hline Arthritis - & 18 & 67 & 85 & \\
\hline Total & 32 & 75 & 107 & \\
\hline
\end{tabular}

positive questionnaire response detected only $44 \%$ of subjects with radiological changes of osteoarthritis; positive findings on physical examination detected only $19 \%$.

On physical examination, bursitis was observed more often over the infrapatellar than the prepatellar bursa. The criteria used to define bursitis on physical examination included detectable swelling or tenderness to palpation, or both. Such findings concerned the infrapatellar bursa in $62 \%$ of cases and the prepatellar bursa in $38 \%$. This finding contrasts with the reported preponderance of prepatellar bursitis in housemaid's knee. ${ }^{1}$

\section{VALIDATION USING PHYSICIAN'S RECORDS}

The attempt to contact physicians to document past episodes of knee disease met with limited success. For example, of 35 floor layers reporting knee tap, we were able to contact the physicians of only 16. In many cases the physician was dead or had retired or the record could not be found. Of the 16 physicians contacted, records were obtained from 12 , all of which confirmed that the patient had undergone needle aspiration of the knee. In seven responses the physician specified that the prepatellar bursa had been aspirated. These limited data suggest that some unquantified fraction of the cases of knee taps among the floor layers represent effusions of the bursae rather than of the joint space.

\section{MULTIVARIATE ANALYSES}

Tables 8, 9, and 10 show the results of stepwise logistic regression analyses to identify those demographic and occupational characteristics that best predicted a history of bursitis, knee taps, and skin infections. Table 8 shows the optimal model for bursitis. Only the self reported score for use of the knee kicker achieved statistical significance in the overall model. The odds ratio was 5.3 when frequent users were compared with non-users. Table 9 shows the corresponding logistic model for knee taps. The two important main effect terms were years of employment and the factor representing kneeling/standing. The negative relation between the $\mathrm{kneeling} / \mathrm{standing}$ factor and knee taps indicates that the probability of knee taps decreases with standing and increases with kneeling.

The statistically significant interaction term between age and the kneeling/standing factor reflects a pronounced difference in the prevalence of reporting knee taps between young and older workers. The probability of knee taps actually decreased with age among workers reporting frequent kneeling (a negative kneeling/standing score), whereas it increased with age among those reporting rare kneeling (a high $\mathrm{kneeling/standing} \mathrm{score).} \mathrm{Such} \mathrm{a} \mathrm{pattern} \mathrm{is} \mathrm{consistent}$ with a survivorship phenomenon, workers with knee 
618

Table 8 Logistic regression model for history of bursitis

\begin{tabular}{lllll}
\hline Variable & $\begin{array}{l}\text { Coefficient } \\
(\beta)\end{array}$ & $\begin{array}{l}\text { Standard } \\
\text { error }\end{array}$ & $\begin{array}{l}\text { Odds } \\
\text { ratio }\end{array}$ & $90 \%$ CI \\
\hline Knee kicker & 0.33 & 0.080 & 5.3 & $2.8-10.3$ \\
\hline
\end{tabular}

Odds ratio and CI computed for heavy users (score $=6$ ) versus non-users (score $=1$ ).

Table 9 Logistic regression model for history of knee taps

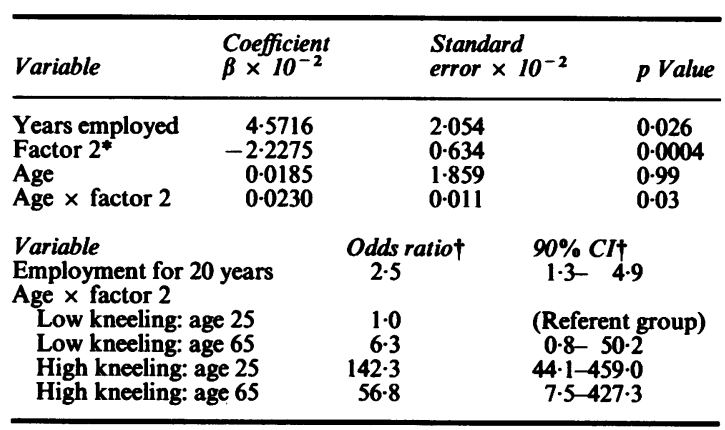

*Factor 2, the kneeling/standing factor, becomes more strongly negative with increased kneeling.

tp values apply to the overall terms in the model. Odds ratios and CIs were computed from the model using the actual scores of study participants with extreme combinations.

Table 10 Logistic regression model for skin infections of the knee

\begin{tabular}{|c|c|c|c|}
\hline Variable & $\begin{array}{l}\text { Coefficient } \\
\beta \times 10^{-2}\end{array}$ & $\begin{array}{l}\text { Standard } \\
\text { error }\end{array}$ & p Value \\
\hline $\begin{array}{l}\text { Factor 1 } \\
\text { Factor 2 } \\
\text { Factor 1-2 }\end{array}$ & $\begin{array}{l}-0.4145 \\
-1.0923 \\
-0.0073\end{array}$ & $\begin{array}{l}0.0040 \\
0.0038 \\
0.00003\end{array}$ & $\begin{array}{l}0.30 \\
0.004 \\
0.035\end{array}$ \\
\hline $\begin{array}{l}\text { Factor } 1 \\
\text { (bending/lifting) }\end{array}$ & $\begin{array}{l}\text { Factor } 2 \\
\text { (kneeling/standing) }\end{array}$ & $\begin{array}{l}\text { Odds } \\
\text { ratio* }\end{array}$ & $90 \% C r^{*}$ \\
\hline $\begin{array}{l}\text { Low bend \& lift } \\
\text { Low bend \& lift } \\
\text { High bend \& lift } \\
\text { High bend \& lift }\end{array}$ & $\begin{array}{l}\text { Low kneeling } \\
\text { High kneeling } \\
\text { Low kneeling } \\
\text { High kneeling }\end{array}$ & $\begin{array}{l}1 \cdot 0 \\
0 \cdot 3 \\
0 \cdot 03 \\
5 \cdot 0\end{array}$ & $\begin{array}{l}\text { (Referent group) } \\
<0 \cdot 1-1.9 \\
<0.01-0.3 \\
1 \cdot 1-22.7\end{array}$ \\
\hline
\end{tabular}

*Odds ratios and CIs were computed from the model using the actual scores of study participants with extreme combinations.

disease tending to self select out of jobs that require extensive kneeling.

Frequent kneeling was also a statistically significant predictor of skin infections of the knee (table 10), but only among workers who also reported a high score for bending and lifting (factor 1). A high kneeling score was not a risk factor among workers with low bending/lifting scores $(O R=0 \cdot 1)$. The possible importance of the interaction between factors 1 and 2 is discussed below.

\section{Discussion}

Carpet and floor layers report substantially more
Thun, Tanaka, Smith, Halperin, Lee, Luggen, Hes knee morbidity than either the general United States white male population or a blue collar working popu市 lation of comparable age, sex, and race. In particular. floor layers describe more frequent bursitis, needle aspiration of knee fluid, skin infections of the knee and miscellaneous other knee conditions. FrequenE reporting of knee problems by carpet layers has beerw noted in a previous survey of musculoskeletal com $\overparen{D}$ plaints among carpet layers in Sweden and is evidenf in the disproportionate number of disability claims for knee injury observed among United States carpeti and floor layers. ${ }^{912}$

To our knowledge, the only previous data abouf knee symptoms in floor layers comes from a Scano dinavian study of 125000 construction workers. ${ }^{12}$ This study, as yet unpublished in English, included, ins a lengthy interview, one question about pain ando stiffness of the knee. Floor and parquet workersis reported the highest prevalence of knee symptoms $\overrightarrow{-}$ among construction workers, 3.3 times higher than that of clerks. Knee disorders have also been studiedin concrete reinforcement workers. ${ }^{13}$ No increase inf physical or $x$ ray abnormalities was found among the reinforcement workers relative to painters. The con $\frac{\mathbb{D}}{3}$ crete workers typically stand rather than kneel, how ever, and their work practices have little in commorn with floor layers.

Our study provides some rather limited informa tion about the clinical features of "carpet layer.' knee." Although we could not define the precises nature and magnitude of the knee disease, we dic determine that effusions are an important comin ponent. About one third of floor layers reported needle aspiration of the knee at some point in thei career. It is not clear whether these effusions involve् predominantly the bursae or the joint space. Our lim $=$ ited follow back to the medical records of worker reporting knee tap found that the effusion involved. the prepatellar bursa whenever a specific diagnosis was mentioned.

The bursitis identified by the rheumatologists in our medical study concerned the infrapatellar bursa. in nearly two thirds of cases. The criteria used foe infrapatellar bursitis were tenderness or swelling in the infrapatellar area or both. Pre- rather tharb infrapatellar bursitis is reported to be the character $\rightarrow$ istic feature among other workers who kneel namely, in housemaid's knee, the beat knee of coaī miners, and the bursitis of clergymen and nuns. ${ }^{1}$

It remains unclear whether carpet layer's knee is also associated with more serious types of knee dis ease, such as osteoarthritis or injury to cartilage and ligaments. That the carpet layers did not report o more frequent history of arthritis and reported les frequent knee surgery than the other trades is nof reassuring. Workers with disabling knee disease 
would be likely to leave the trade and be lost from a cross sectional study such as ours. There are three lines of indirect evidence that floor layers with serious knee morbidity may indeed leave the trade. Firstly, symptoms of knee disease increase with age in the general population but decrease with age among floor layers, suggesting that symptomatic floor layers change their occupation. Secondly, there is a 100 -fold increase in compensation claims among floor layers over other trades, but only a three to six fold increase in symptom prevalence in our study. This difference may be explained by floor layers leaving because of disability. Thirdly, and finally, there is anecdotal reporting by floor layers that colleagues with serious knee problems leave to find other work. Although we attempted to deal with this problem of selective retirement by including former workers, we were only able to locate retired workers who continued to pay union dues. The motivation to pay such dues is directly related to seniority-for example, only one of the retired floor layers in our study had stopped work prematurely with less than 20 years seniority. Thus the retired study participants are a "survivor" population and may not include workers of shorter tenure who left prematurely due to knee disability.

We were partly successful in identifying the occupational determinants of carpet layer's knee. Multivariate statistical analyses of the questionnaire data showed that a worker's self reported score for using a knee kicker, an instrument used only by the carpet layers, was the single important determinant of bursitis. Kneeling, and its interaction with age, were predictors of knee tap. The distinction between knee taps and bursitis is interesting but difficult to interpret. We cannot determine whether knee taps represent aspiration of bursae in cases of severe bursitis or aspiration of the joint space.

A second interesting finding of the regression analyses is the interaction between factor 2 (kneeling/standing) and factor 1 (bending/lifting) in the model for skin infections of the knee (table 10). It seems biologically plausible that workers who kneel frequently and bend and lift, particularly while kneeling, might be at high risk of skin infections. It is not clear why bending and lifting should be protective in workers who kneel infrequently. We suspect that this finding, if real, is due to some unidentified correlate of bending and lifting rather than these activities perse.

The prevalence of many reported knee problems was as high or higher among the small group of tile terrazo and marble workers than among the carpet layers. Despite the small study population, tilesetters reported conditions such as arthritis significantly more frequently than did the MWBL. The tilesetters, or non-resilient floor layers, spend their workdays kneeling on hard, unyielding surfaces. Although they do not use the knee kicker, these workers undoubtably experience occupational knee trauma.

Similarly, the comparison population of millwrights and bricklayers kneel frequently in their work (table 4). Such kneeling may account for some of the increased symptom reporting (table 6) and workers' compensation claims (table 1) filed by these workers. Knee trauma occurs in many construction trades and it is difficult to find an unexposed yet comparable comparison group.

The implications of carpet layer's knee are clearly most immediate for the 80-100000 carpet and floor layers (SOC 6162) for whom it carries both medical and economic consequences. ${ }^{14}$ The number of these workers is substantial, although small in relation to the general population. Of potentially larger public health consequence are the incompletely understood effects of chronic kneeling in a variety of trades.

In summary, a cross sectional questionnaire study of knee symptoms among three groups of current and retired construction workers showed that carpet and floor layers report an increased frequency of bursitis, needle aspiration of knee fluid, skin infections of the knee, and a variety of knee symptoms compared with millwrights and bricklayers. Tile terazzo and marble setters report similar problems. Medical examinations on a subset of subjects served to validate the questionnaire data. Further research is needed to (1) characterise the nature and extent of knee disease in workers who incur chronic knee trauma, and (2) develop an effective, ergonomically suitable substitute for the knee kicker for stretching carpet.

We thank the members and officials of the three local unions who made the study possible. We also wish to thank the faculty members of the division of immunology, department of internal medicine, and the department of radiology, University of Cincinnati College of Medicine, who conducted the medical and $x$ ray examinations. Drs Nortin Hadler, Vern PutzAnderson, and Craig Anderson were extremely helpful in their review of the protocol and of the manuscript for publication.

\section{Appendix A}

QUESTIONS CONCERNING PAST KNEE

CONDITIONS, NIOSH QUESTIONNAIRE*

(1) Have you ever had your knee tapped for an accumulation of fluid or blood in the knee joint?

(2) Have you ever had bursitis (inflammation of a joint sac) of the knee?

(3) Have you ever had arthritis of the knee?

(4) Have you ever had a skin infection in the knee joint area?

(5) Have you ever had a broken knee cap? 
(6) Any other illness or injury to the knee joint?

(7) Have you ever had any operation (surgery) of the knee joint?

*For each positive response, the subject was asked in what year the condition first occurred, last occurred, in which leg it occurred, and the name of the physician treating the problem.

\section{Appendix B}

The questions adopted from the National Health and Nutrition Survey included:

(1) Have you had pain in or around the knee on most days for at least one month?

(2) When this knee pain is present, does it hurt at rest as well as moving?

(3) When this knee pain is present, is there also swelling of the knee joint?

(4) When this pain is present, have you ever had "locking" of the knee?

(5) Has either knee "given away" under you?

(6) Have you ever had any swelling of joints with pain present when the joint was touched on most days for at least one month? (This is a two step question. The second part asks which joint is affected.)

(7) Have you had stiffness in your joints and muscles when getting out of bed in the morning on most mornings for at least one month? (This is a two step question. The second part asks which joint is affected.)
Thun, Tanaka, Smith, Halperin, Lee, Luggen, Hess $\overline{\frac{c}{\alpha}}$

\section{References}

1 Hunter D. The diseases of occupations. London: Hodder and Stoughton, 1978:780-5.

2 Collis EL, Llewellyn TL. Report on miners beat knee, beat hand, and beat elbow. London: Medical Research Council, 1924:5-49. (Special report series, No 89.)

3 Atkins JB, Marks J. The role of staphylococcal infection in beat disorders of miners. Br J Ind Med 1952;9:296-302.

4 Watkins JT, Hunt TA, Fernandez HP, Edmonds OP. A clinical study of beat knee. Br J Ind Med 1958;15:105-9.

5 Sharrard WJ. Pressure effects on the knee in kneeling miners. $A m m$ R Coll Surg 1965;36:309-24.

6 Williamson DM. Beat diseases. In: Rogan JM, ed. Medicine in the mining industries. Philadelphia: FA Davis Co, 1972:199-208.

7 Mueller MR, Bhattacharya A. A study of postural changes associated with carpet installation. In: Mital A, ed. Trends in ergonomics/health factors I. Amsterdam: Elsevier, 1984:59-64. Э

8 Root N, McCaffrey D. Producing more information on work injury and illness. Monthly Labor Review 1978;101:16-21.

9 Tanaka S, Smith AB, Halperin W, Jensen R. Carpet-layer's knee. $N$ Engl J Med 1982;307:1275-6.

10 Maurer K. Basic data on arthritis knee, hip, and sacroilliac joints in adults ages 25-74 years, United States, 1971-1975. Hyattsville, 윽 MD: US Department of Health, Education, and Welfare, Public Health Service, Office of Health Research, Statistics and Technology, National Center for Health Statistics, 1979. (DHEW publ No (PHS) 79-1661.)

11 Kleinbaum DG, Kupper LL, Morgenstern H, eds. Epidemiologic research, principles and quantitative methods. Belmont, California: Lifetime Learning Publications, 1982.

12 Ekstrom H, Engholm G, Nyqvist B, Wallenquist A. Knee pains, an occupational medical problem. Stockholm: Bygghälsans Forskingsstiftelse, 1983.

13 Wickstrom G, Hanninen K, Mattsson T, et al. Knee degeneration in concrete reinforcement workers. $\mathrm{Br} J$ Ind $\mathrm{Men}$ 1983;40:216-9.

14 US Department of Labor, Bureau of Labor Statistics. Current population survey, employment and earnings, January 1985. Vol 32, No 1. Superintendent of Documents, US Government Printing Office, 1985: 129. 